\title{
Stapleless Laparoscopic Sleeve Gastrectomy: a Relatively New Approach in Bariatric Surgery
}

\author{
C. Rajkumar Vinayak ${ }^{1}$ - Sivaneswaran Lechmiannandan ${ }^{1} \cdot$ Umasangar Ramasamy $^{1}$
}

Published online: 27 September 2016

(C) The Author(s) 2016. This article is published with open access at Springerlink.com

Laparoscopic sleeve gastrectomy (LSG) has been established as an effective procedure for the treatment of morbid obesity gaining popularity over the last decade as an effective single procedure of bariatric surgery [1]. The cost incurred however has been of major concern as the stapler power gun and staple materials are expensive. Hence, the need arose for stapleless bariatric surgery. Jacques Himpens of Belgium pioneered stapleless bariatric surgery by performing a laparoscopic Roux-en-Y gastric bypass (LRYGB) utilizing the LigaSure Atlas (LSA) and over sewing the wound edges with nonabsorbable synthetic sutures. He used this stapleless technique for 10 patients as laparoscopic procedures, such as duodenal switch, sleeve gastrectomy, and Roux-en-Y gastric bypass. The operating time was not significantly lengthened, and no ill effects were recorded [2].

In 2005 at the International Federation for the Surgery of Obesity and Metabolic Disorders (IFSO) meeting held in Maastricht, Netherlands, Almino Ramos and colleagues presented a video demonstration of a stapleless Roux-en-Y Gastric Bypass (RYGB) utilizing the LSA and went on to publish their work in 2006 [3]. In 2013, Masoud Rezvani and colleagues from Abington Memorial Hospital, Pennsylvania, published a single report on Robotic Stapleless LSG, and in February 2016 at the Annual Conference of Obesity and Metabolic Surgery Society of

C. Rajkumar Vinayak

rajkumarvnyk@yahoo.com

Sivaneswaran Lechmiannandan

smartsiv@ hotmail.com

Umasangar Ramasamy

drumasangar69@gmail.com

1 Department of Surgery, Taiping Hospital, Taiping, Perak, Malaysia
India (OSSICON) in India, Shashank Shah and colleagues presented a video of stapleless LSG [4]. Upon literature search, only the above-mentioned publications and presentations have described stapleless bariatric surgery. However, LSG technical details were not described in depth by any of the authors.

Being in a unique situation where we perform high-volume bariatric surgeries at a non-tertiary center, financial constraints have become a major limiting factor. Stapleless LSG seems a promising option to offset these constraints and to benefit the community. Based on the early experience of Shashank and colleagues, we would like to propose a stapleless laparoscopic sleeve gastrectomy technique.

A 36-Fr gastric bougie will be used for gastric calibration as per our standard sleeve gastrectomies. In this new approach, 1 to $1.5 \mathrm{~cm}$ distance from gastric bougie will be calculated for gastric transection. We have derived this measurement for suturing after calculating the possible lateral thermal spread which is 1 to $2 \mathrm{~mm}$ beyond the thermal device (LigaSure) and the seal width of $3 \mathrm{~mm}$ on either side of the blade. Therefore, the suturing of the first layer requires a minimum of 4-5 $\mathrm{mm}$ distance from the sealed/partially sealed gastric wall edge (a visual marker was also used - white coagulated tissue transition line/zone on anterior and posterior walls). The remaining $1 \mathrm{~cm}$ of tissue will be for imbricating the first layer. The above measurements also took into consideration the width of standard stapler devices which typically measures $1 \mathrm{~cm}$ in width and $5 \mathrm{~mm}$ on each side of the blade (often extra tissue is left to facilitate reinforcement of staples line). No guideline exists as to the amount of tissue needed so far.

Next, interrupted stay sutures are placed every 3 to $4 \mathrm{~cm}$ along the margin with 2/0 absorbable sutures, Polysorb (glycolic and lactic acid, Covidien) to keep anterior and posterior neogastric walls well oriented for suturing. For the first layer, continuous intermittent locking suturing is done from transected cardiofundic area to antrum with 2/0 Polysorb sutures. For the second 
layer, extra mucosal running suturing is done, imbricating the first layer with 2/0 Unidirectional V-LOC, $30 \mathrm{~cm}$ (Covidien) suture. The V-LOC loop was not utilized; instead, knotting was done to ensure secure locking of suture end, thus, replicating standard open general surgical principles of tissue transection and suturing, laparoscopically.

We plan to conduct a pilot study on stapleless LSG to assess its safety and efficacy on patients. In view of the low cost needed to perform the surgery, we do hope that more patients can benefit from bariatric surgery which is known as the effective surgical method to reduce weight in obese patients and improve obesityrelated co-morbidities.

\section{Compliance with Ethical Standards}

Conflict of Interest The authors declare that they have no conflict of interest.

Ethical Approval For this proposed technique, to establish its safety and efficacy, a pilot study is being undertaken. The study is registered in the National Medical Research Registry (NMRR), Ministry of Health Malaysia with NMRR ID: NMRR-16-1411-31808.
Consent Statement It does not apply at this stage.

Open Access This article is distributed under the terms of the Creative Commons Attribution 4.0 International License (http:// creativecommons.org/licenses/by/4.0/), which permits unrestricted use, distribution, and reproduction in any medium, provided you give appropriate credit to the original author(s) and the source, provide a link to the Creative Commons license, and indicate if changes were made.

\section{References}

1. Carlin AM, Zeni TM, English WJ, Hawasli AA, Genaw JA, Krause $\mathrm{KR}$, et al. The comparative effectiveness of sleeve gastrectomy, gastric bypass, and adjustable gastric banding procedures for the treatment of morbid obesity. Ann Surg. 2013;257(5):791-7.

2. Himpens J, Leman G, Sonneville T. Laparoscopic Roux-en-Y gastric bypass performed without staples. Surg Endosc. 2005;19(7):1003.

3. Ettinger JE, Ramos AC, Azaro E, Galvão-Neto MP, Mello CA, Galvão MS, et al. Staplerless laparoscopic gastric bypass: a new option in bariatric surgery. Obes Surg. 2006;16(5):638-45.

4. Rezvani M, Sucandy I, Antanavicius G. Totally robotic staplerless vertical sleeve gastrectomy. Surg Obes Relat Dis. 2013;9(5):e79-81. 